\title{
Konfokal Raman Mikroskobu ile Bilinmeyen Polimer Tabanlı Bir Kompozit Malzemenin Tanımlanması ve Kemometrik Yöntem Kullanarak Karışım Oranlarının Belirlenmesi
}

\author{
Defining an Unknown Polymer Based Composite Material by Confocal Raman Microscopy \\ and Determination of Mixing Ratios Using Chemometric Method
}

\author{
Nusret KAYA* \\ İzmir Katip Çelebi Üniversitesi, Merkezi Araştırma Laboratuvarları, Uygulama Araştırma Merkez Müdürlü̈̆̈̈. Balatçı-Çiğli, İzmir
}

• Geliş tarihi / Received: 06.06.2019 • Düzeltilerek geliş tarihi / Received in revised form: 11.11.2019 • Kabul tarihi / Accepted: 25.11 .2019

$\ddot{O} \mathbf{z}$

$\mathrm{Bu}$ çalışmada tersine mühendislik uygulamalarında yaygın olarak kullanılan ve bilinmeyen analizlerinde güçlü bir analiz metodu olan, Eş Odaklı Raman mikroskopisi yöntemi kullanılarak türü bilinmeyen bir Polimerik kompozit malzemenin moleküler yapısından yola çıkarak polimer türü ve dolgu malzemeleri tanımlanmaya çalışılmıştır. İleri araştırmalarda kullanılan kemometrik yöntemler ile yapısı analiz edilen kompozit malzemenin, yapısını oluşturan her bir bileşiğin, kompozit yapısı içindeki miktarsal oranı araştırılmıştır. Kompozit malzemenin kullanım alanı dışında hiçbir veriye sahip olunmadığı için içeriğindeki malzemeler ile ilgili hiçbir yakınsama yapılmayarak sadece analizi yapılan kompozitin mikroskop görüntüsü altında her bir farklı kısmından elde edilen Raman spektrumları kütüphane taraması ile eşleştirilmiştir. Yapılan eşleştirmelerde en yüksek eşleşme oranına sahip malzeme olduğu varsayılarak analizler ve hesaplamalar bu doğrultuda devam ettirilmiş̧ir. Eş Odaklı Raman mikroskobu ile kompoziti oluşturan üç ana bileşik üzerine yoğunlaşılarak malzeme yüzeyinde haritalandırma yapılmıştır. Kompoziti oluşturan üç ana bileşenin sırası ile polipropilen (PP), silisyum karbür $(\mathrm{SiC})$ ve karbon fiber $(\mathrm{KF})$ olduğu anlaşıılmıştır. Bu üç bileşenin, kompozit içindeki hacimce oranları 20X optik büyütme altında, sırası ile \%60, \%26, ve \%14 olarak hesaplanmıştır. Eş Odaklı Raman mikroskopu tekniği kompozit malzemelerin içine katılan ve kompozite artı özellik katan tüm malzemelerin tanımlanmasında kullanılabilecek ileri bir enstrümantal analiz yöntemi olduğu görülmüştür.

Anahtar kelimeler: Eş Odaklı Raman Mikroskobu Spektroskopisi, Kemometri, Kompozit

\begin{abstract}
In this study, it has been tried to define polymer type and filler materials based on the molecular structure of an unknown type of Polymeric composite material by using the Confocal Raman Microscopy method which is a powerful method of analysis used in reverse engineering applications. The amount of the composites in the composite structure of the composite material, whose structure was analyzed by the chemometric methods used in advanced research, was investigated. Since there is no data other than the usage area of the composite material, no convergence is made about the materials in its content and only the Raman spectra obtained from each different part of the composite under the microscope image of the analyzed composite were matched with the library survey. Assuming that the material with the highest match ratio was matched, the analyzes and calculations were continued in this direction. The Confocal Raman Microscope was focused on the three main compounds that were polypropylene (PP), silicon carbide (SiC) and carbon fiber $(C F)$, mapped on the surface of the material. The ratios of these main components of the composite were calculated as 60\%, 26\%, and 14\% under $20 X$ optical magnification, respectively. Confocal Raman microscopy technique has been seen an advanced instrumental analysis method which can be used to identify all the materials that are incorporated into composite materials.
\end{abstract}

Keywords: Confocal Raman Microscopy Spectroscopy, Chemometry, Composite

*Nusret KAYA; nnusrettersunn@gmail.com, Tel: (0232) 32935 35, orcid.org/0000-0003-1727-3155 


\section{Giriş}

Spektroskopik analiz teknikleri günümüzde birçok alanda kullanılmaktadır. Kimyasal yapı tayininde yaygın olarak kullanılmakta olan bu analiz tekniği, ışığın belli bir dalga boyunun veya geniş bir dalga boyu aralığının kullanılması ile madde ile etkileşimini inceler (Hollas, 1984). Basit UltraViyole bölge analizlerinden günümüzde tek dalga boyundaki lazerle yapılan spektroskopik analiz metotlarına kadar birçok farklı 1şık kaynaklı spektroskopik yöntem geliştirilmiştir (Keren vd., 2008; Moerner ve Fromm, 2003; Stuart, 2000).

Titreşimsel spektroskopisi, maddenin yapısında bulunan atomlar arasındaki bağların infrared (IR) ışınlarını emmesi veya saçması üzerine kurulu bir spektroskopi dalı olarak karşımıza çıkar. Homo nükleer yapıdaki moleküller hariç, tüm moleküller IR spektrumu verebilirken, homo nükleer moleküller polaritelerden dolayı Raman'da sinyal verirler (Colthup, 2012). Molekülleri oluşturan bağların hareketlerinin bazıları IR aktif iken bazıları Raman aktif olabilirler, bu da iki farklı ışık kaynağına sahip ölçüm tekniğinin birbirlerini tamamlayıcı analiz yöntemleridir. Titreşimsel spektroskopisi, bir maddenin nicel veya nitel analizinin yapılmasında yaygın olarak kullanılmasına rağmen en çok nitel analizlerde kullanılana bir yöntemdir.

1931 y1lında Nobel fizik ödülü alan C.V. Raman görünür bölgede gelen bir 1şının maddenin molekülleri etkileşime girdiği ve saçılan ışının küçük bir kısmının farklı dalga boyunda olduğunu keşfetmiştir (Raman, ve Krishnan, 1928). Kullanılan 1şığın monokromatik olması farklı dalga boyunda saçılan az miktarda ışının incelenmesine olanak sağlar. Madde ile etkileşime giren monokromatik 1şık temelde üç farklı şekilde geri yansir (Chance ve Spurr, 1997). Yansımalardan biri elastik saçılma; maddeyle etkileşime giren monokromatik 1ş1k dalga boyunda ve enerjisinde herhangi bir değişiklik olmadan yansır (Ball, 2001). Maddenin moleküllerinin, madde ile etkileşime giren monokromatik ışığın dalga boyundan daha büyük bir dalga boyunda 1şı ile yansıması olayına elastik olmayan saçılma denir. Elastik olmayan saçılmalar maddeyi oluşturan moleküllerin bağlarındaki titreşimden kaynaklanan dipol moment farkından kaynaklanır (Keresztury, 2006). Bunların haricinde diğer bir 1 şık madde etkileşiminde, monokromatik ışının maddenin molekülleri tarafindan absorblanmasıdır. $\mathrm{Bu}$ absorbloma olayı, moleküller bağları oluşturan elektronların 1şık ile etkileşime girerek, elektronların farklı molekül yörüngelerine transfer olmaları ile gerçekleşir (Banwell, C.N. ve McCash, 1994). Raman spektroskopisinde elastik olmayan saçılma yapan 1şın grubuna odaklanılır. Monokromatik 1şık kaynağ 1 olarak bir lazer kaynağ1 bu spektroskopik analiz tekniğinde yaygın olarak tercih edilir. Elastik olmayan ışınlar bir detektör üzerine düşürülmek suretiyle sinyale dönüştürülür. Elde edilen sinyaller atomlar aras1 bağlara özgü oldukları için oluşturdukları spektrumun kendilerine özgü bölgelerinde gözlemlenir.

Eş odaklı Raman mikroskobu tekniği, Raman analizinin bir mikroskop yardımı ile beyaz ışık altında mikroskopta belirlenen bölgeye lazer ışığının uygulanması ve elastik olmayan 1 şık yansımalarının detektöre düşürülerek sinyale dönüştürülmesi olarak tanımlanabilir (Dieing vd., 2011). Bu teknik sayesinde karmaşı malzeme yapılarının analizinden daha sağlıklı sonuçlar elde edilir. Birçok organik ve inorganik malzemelerin bir araya getirilmesinden oluşan malzemelerin içeriklerinde bulunan maddelerin tanımlanmasında yaygın olarak kullanılmaya başlanmıştır (Cai vd., 1998; Caspers vd., 2003; Gierlinger ve Schwanninger, 2006; Hartschuh vd., 2003; Klein vd., 2012). İlaç etken madde miktarının (Belu vd., 2008), hazırlanan tabletlerdeki dağılımı ve miktarı ile ilgili verdiği bilgilerden dolayı kalite kontrol amaçlı birçok ilaç firmasında kullanılmaya başlanmıştır (Breitenbach vd., 1999). Biyolojik örneklerde yapılan çalışmalarda, mikrobiyolojik aktivitenin, mikrobiyolojik türlerin tanımlanmasında ve DNA gibi moleküllerin hücre içindeki yerleşimlerinin analizinde kullanılmaya başlanmıştır (Uzunbajakava vd., 2003). Tüm bu çalışmaların dışında tersine mühendislik uygulamalarında ikame mal üretimlerinde var olan bir ürünün yapısı bu yöntemle tayin edilebilir.

Yapılan bu çalışmada kimyasal kompozisyonu bilinmeyen bir polimer tabanl 1 kompozit malzemenin bileşenleri araştırılmıştır. $\mathrm{Bu}$ bileşenler üzerinden kompoziti oluşturan maddelerin, kompozit malzemenin bir kesitinin yüzeyinin haritalandırılarak kemometrik yöntem ile içindeki bileşenlerin hacimce miktarları hesaplanmıştır. Kemometri uzun zamandır kimyasal verilerin matematiksel ve istatistiksel yöntemlerle daha iyi anlaşılmasını sağlayarak, kalite parametreleri veya fiziksel özellikler ile ilgili bilgilerin ilişkilendirilmesinin sağlandığı bir yöntemdir. Moleküler olarak elde edilen tüm veriler belirli bir matematiksel ve istatistiki algoritma ile hesaplanarak benzerlikleri ortaya 
koyulabilir. $\mathrm{Bu}$ benzerlikten yola çıkarak malzemenin sınıflandırılması ve analizi kolaylaşır.

\section{Deneysel Çalışmalar}

Tersine mühendislik uygulamalarına yönelik yapılan bu çalışmada Renishaw marka Invia model eş odaklı Raman cihazı kullanılmıştır. Cihaz ayn1 zamanda Leica model mikroskop sistemine bağlı olan dört farklı lense sahiptir. Bu optik sisteme bağlı olarak $532 \mathrm{~nm}$ ve $785 \mathrm{~nm}$ olmak üzere iki farklı lazer kaynağı mevcuttur. $\mathrm{Bu}$ lazer kaynakları ile çalışabilen sırası ile 600, 1200,1800 ve 2400 olmak üzere dört farklı kırınım ağı, uygun dalga boyu aralığında sinyal elde edilebilmesine olanak sağlar. Geniş bir Raman Kütüphanesi olan cihazın yazılımı Wire-4 altında çalıştırılabilerek bilinmeyen analizlerinde karşılaştırmayı destekler. Bunun dışında farklı amaçlarla kullanılan birçok kütüphane ile çalıştırılabilen yazılım cihazın kullanımı ile ilgili esneklik sunar.

Bilinmeyen polimer tabanlı kompozitin bütün analizlerinde $785 \mathrm{~nm}$ dalga boyunda lazer kaynağ 1 ve $1200 \quad 1 / \mathrm{mm}$ kırınım ağ1 kullanılmıştır. Numuneden alınan kesit, 5x, 20x, 50x ve 100x optik büyütme oranları altında incelenmiştir. Kompozit malzemenin içindeki polimer kısımdan farklı olan bölgeler detaylı olarak ele alınmış ve malzeme ile ilgili ön bilgiler toplanmıştır. Malzemeyi oluşturan yapılar ve şekilsel özellikleri bu inceleme ile elde edilmiştir. Kompozit malzemeyi oluşturan parçacıkların boyutları göz önüne alınarak en uygun spektroskopik inceleme için optik lensin 20x olduğuna karar verilmiş ve tüm spektroskopik analizler bu büyütme oranında yapılmıştır.

\section{Bulgular ve Tartışma}

Beyaz 1şık altında malzemenin topografyasının düzgün olduğu bölgelerden fotoğraflar çekilerek, incelemeye en uygun bölge belirlenmiştir. $\mathrm{Bu}$, kompozitin içinde bulunan katkı malzemelerinin hepsinin bir arada bulunduğu ve homojen dağılım gösterdiği alanı incelemek için tercih edilmiştir. Şekil 1'de 20x optik büyütme altında içeriği bilinmeyen kompozit malzemenin beyaz 1 şı altındaki görüntüsü mevcuttur. $\mathrm{Bu}$ görüntüden malzemenin matris kısmını oluşturan polimerin ve içinde bulunan katkıların yapısal farklılıkları kolaylıkla ayırt edilebilmektedir.

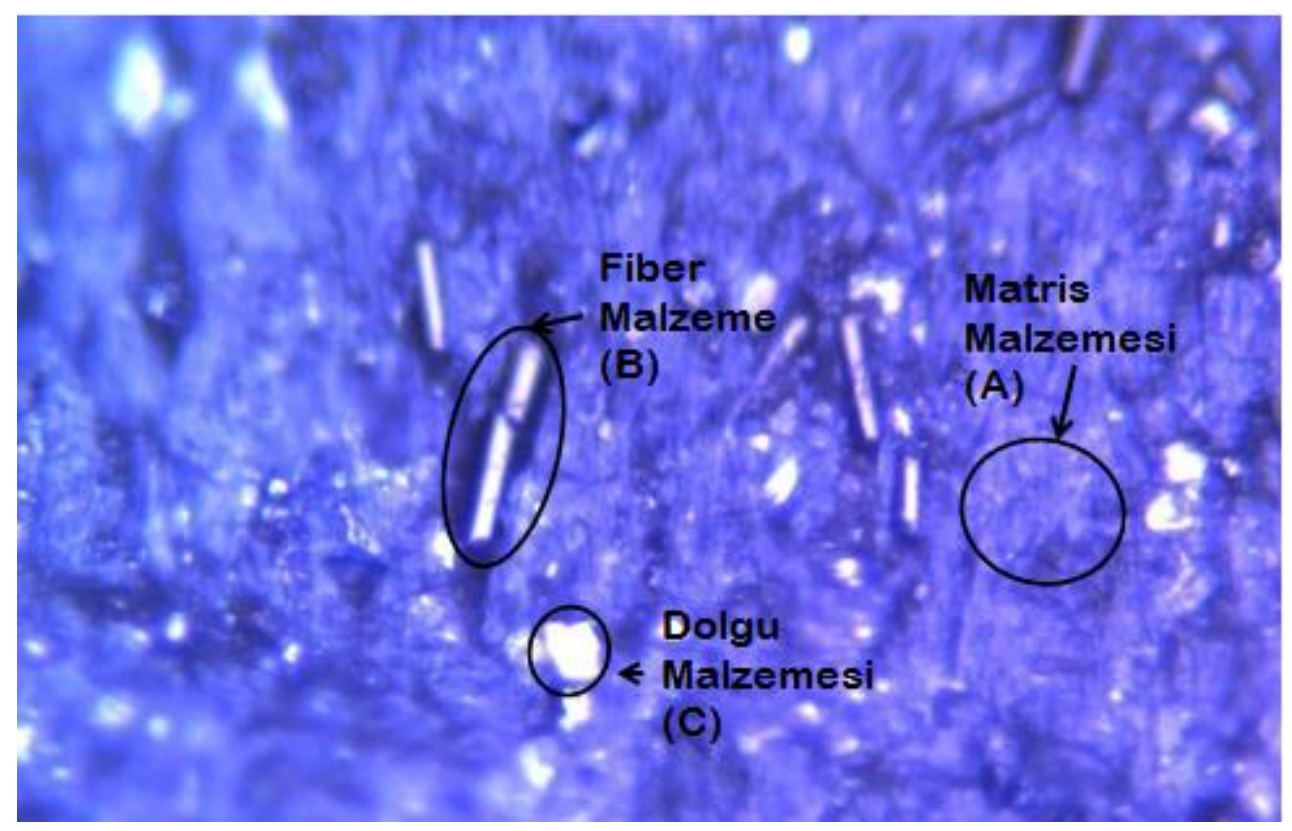

Şekil 1. Bilinmeyen kompozit malzemenin 20X optik büyütme altındaki görüntüsü

Yapıda üç temel kısmın olduğu anlaşılmıştır. Bunlardan birincisi matris malzemenin olduğu ve A bölgesi olarak işaretlenmiş alandır. Bu bölgenin spektral analizi $785 \mathrm{~nm}$ lazer kaynağ 1 ve $0,43 \mathrm{~W}$ lazer gücü ile 10 saniye etkileşme süresi baz alınarak analiz adilmiş ve Şekil 2'de verilen A spektrumuna ulaşı1mıştır. Spektrumun 2691-3073 cm-1 bölgesi, C-H bağlarının yoğun olduğu bir alan olduğu anlaşılmıştır. $\mathrm{Bu}$ da bu bölgenin malzemenin polimer bölgesi olabileceğini göstermiştir. Polimer yapının spektrumlarında görülen $\mathrm{C}-\mathrm{H}$ bağlar1; 808, 841, 998, 1435 ve 1458 $\mathrm{cm}^{-1}$ de sirası ile C-H dönme, $-\mathrm{CH}_{3}$ dönme ve $\mathrm{CH}_{2}$ eğilme ile polarizasyon yaratarak spektral bantlar oluşturmuştur (Vardeny vd., 1983). Bu bağlar ile ilgili yapılan kütüphane karşılaştırması ve literatür taraması ile malzemenin isotaktikpolipropilen (iPP) olduğu belirlenmiştir 
(Nielsen vd., 2002). Bu yolla malzemenin matris kısmı ortaya çıkarılmıştır.

Beyaz 1ş1k altındaki görüntüden elde edilen bir başka yapıda silindirik şekilde olan fiber malzemedir. $\mathrm{Bu}$ fiberlerin yapısal özelliklerine bakıldığında yaklaşık çapının 80-100 mikron büyüklüğe sahip olduğu, boylarının da 2-4 mm arasında değişiklik gösterdiği görülmüştür. Fiber yapının moleküler yapısı matris analizindeki parametrelerle analiz edilerek Şekil 2'deki B spektrumu elde edilmiştir. B spektrumunda görülen $1303 \mathrm{~cm}-1$ (D-bant) ve $1587 \mathrm{~cm}-1$ (Gbant) bantlarının, C-C bağlarının gerilme ve eğilme hareketlerine ait polarizasyon olduğu görülmüştür. $\mathrm{Bu}$ alandan elde edilen spektral veriler incelendiğinde malzemenin karbon fiber olduğu net olarak anlaşılmıştır (Qian vd., 2019). Fiber malzemenin olduğu alan, B bölgesi olarak isimlendirilmiştir.

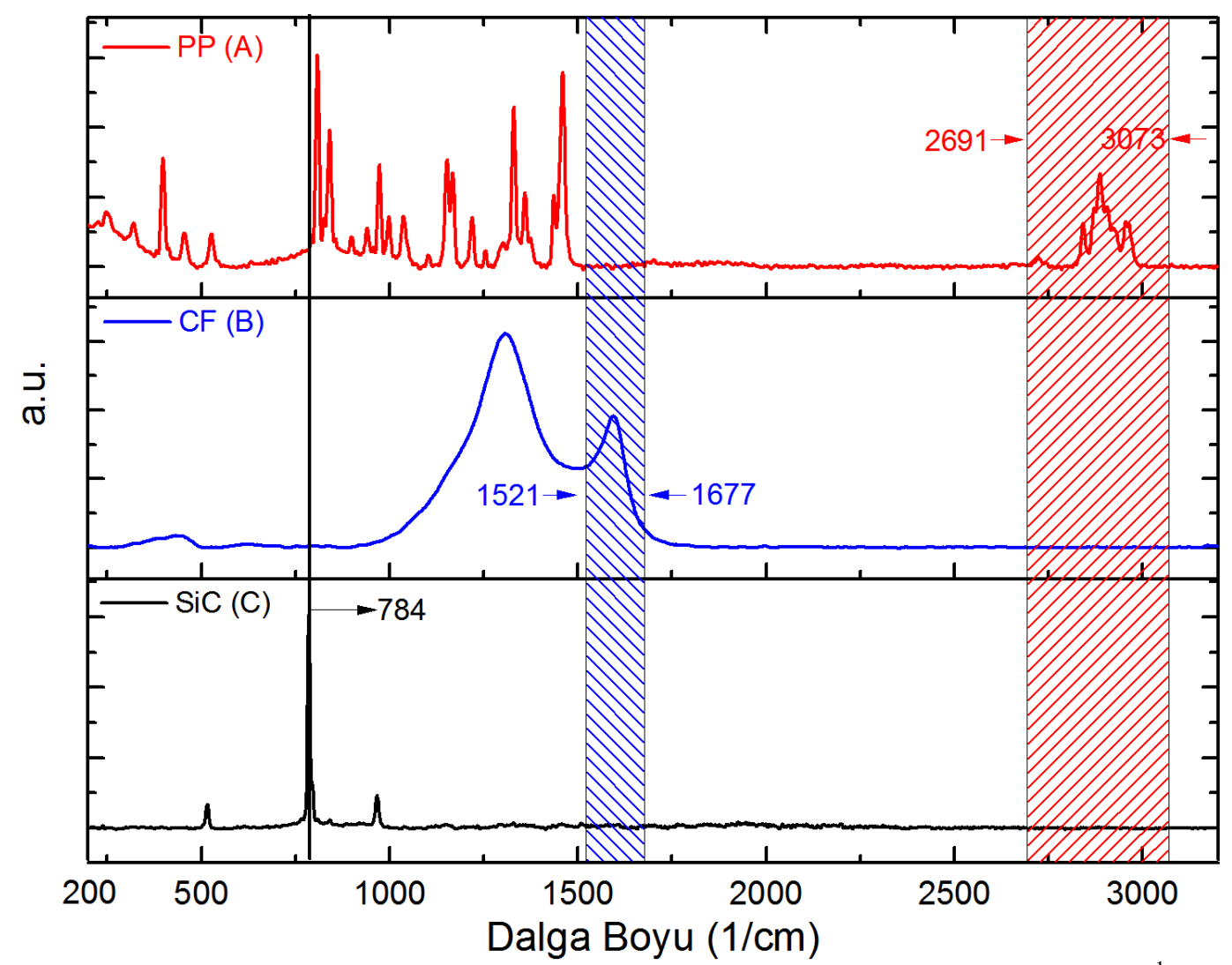

Şekil 2. Bilinmeyen kompozit malzeme içinde bulunan üç farklı yapının $200-3200 \mathrm{~cm}^{-1}$ dalga boyları arasındaki Raman spektrumları.

Kompozitin içinde şekilsel ve büyüklük olarak homojen olmayan ama dağılımsal bakıldığında iyi bir dağılım gösteren üçüncü bir maddeye rastlanmıştır. Malzemenin parçacık büyüklügünün 1-30 mikron arasında değişiklik gösterdiği beyaz ış1k altındaki görüntüden anlaşılmaktadır. Malzemenin ana piki $784 \mathrm{~cm}^{-11}$ de çok şiddetli ve keskin bir pik vermiştir. Bu malzemenin analizi de matris ve fiber analizinde kullanılan metotla analiz edilerek, C spektrumu Şekil 2'deki spektral veri elde edilmiştir. Elde edilen spektrum kütüphane karşılaştırması ve sinyali yüksek olan piklerin literatürde araştırılması ile bu amorf yapılı parçacıkların bir tür teknik seramik olan silisyum karbür olduğu belirlenmiştir (Okumura vd., 1987).

Artık temel anlamda kompozitin bileşenleri bilindiği için kompoziti oluşturan bu malzeme- lerin kompozit içinde ne kadar bulundukları araştırmak amacı ile yeni bir metot oluşturmaya ihtiyaç duyulmuştur. Bu metot cihazın yazılımının altında gelen ve birçok yüzeysel analiz işlemi yapmaya olanak sağlayan, yüzeyi tarayarak spektral bir harita çıkartabilen yüzey haritalama metodudur. $\mathrm{Bu}$ metot, beyaz 1 şı altındaki görüntüde belirlenen bölgenin spektral analizi için $100 \mathrm{~nm}$ hassasiyetle bölgelere ayırır ve her bölgeden toplanan spektral veriler program tarafından kullanıcıya bir arayüz yardımı ile aktarılır. Kompozitin yüzeyinde işaretlenen yaklaşık 1000 mikrona 1000 mikronluk alan 12000 eşit parçaya bölünerek her parçadan, 785 $\mathrm{nm}$ lazer kaynağı ve 0,1 saniye etkileşim süresi ile 12000 spektrum çekilmiştir. Elde edilen tüm spektrumlar yüzeyin tamamının bir moleküler gözlükten bakılan görüntülerini elde etmemizi sağlayan bir pencere yaratmıştır. 


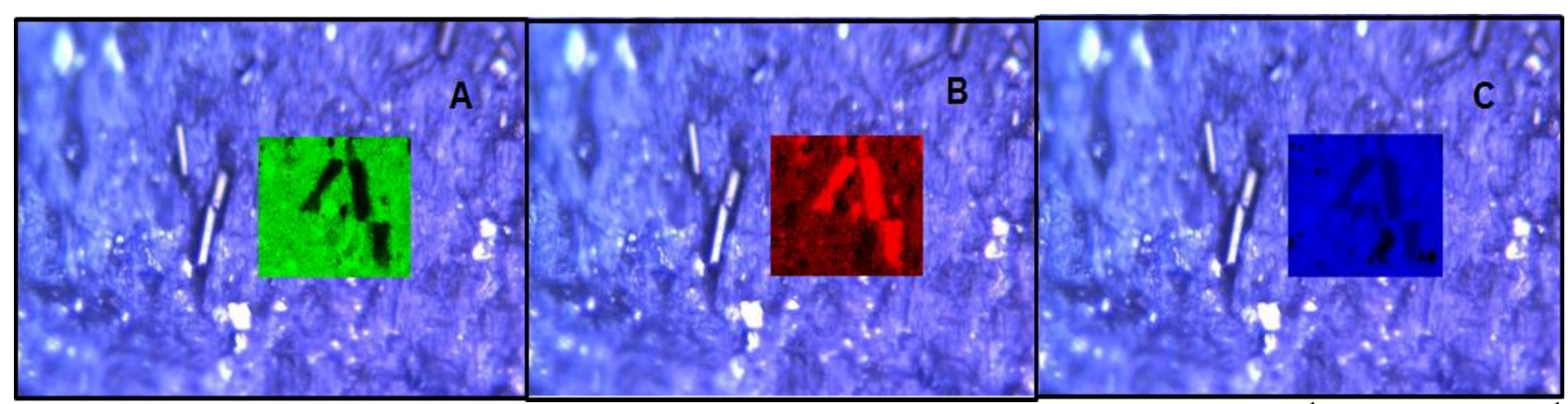

Şekil 3. Bilinmeyen kompozit malzeme içinde bulunan üç farklı yapının sırası ile $800 \mathrm{~cm}^{-1}, 1200-1500 \mathrm{~cm}^{-1}$ ve $2500-2800 \mathrm{~cm}^{-1}$ dalga boyu arası renkli spektral taramas1

Spektral verilerin ayrıştırılması ve tasnif edilerek hangi malzemeden geldiğinin belirlenmesi için yazılımın altında bulunan ve bu aramayı kolaylaştıran matematiksel algoritmadan faydalanmak mümkündür. SiC'in en kuvvetli sinyali olan $800 \mathrm{~cm}-1$ deki bandının olduğu tüm spektrumları farklı renkte renklendirildiğinde, Şekil 3'deki A görüntüsü elde edilmiştir. Bunun haricinde, iPP'nin bulunduğu bölgeyi incelemek için kompozitteki diğer iki malzemeden farklı bölgede verdiği Raman bantları tercih edilmişsir.
KF bantları ile bazı iPP bantları çakıştı̆̆ için spektrumun yüksek dalga boyu bölgesinde gelen C-H bağlarının olduğ $2500-2800 \mathrm{~cm}^{-1}$ aralığ tercih edilmiştir. $\mathrm{Bu}$ aralıkta Raman band1 bulunduran spektrumlar yazılım ile taranarak Şekil 3'deki C görüntüsü elde edilmiştir. KF malzemesinin spektral verisinden de malzemenin amorf karbon olduğunu tanımlayan 1500-1200 $\mathrm{cm}^{-1}$ aralığındaki bantlar seçilerek bu bantlar spektral veri içinde taranıp, Şekil 3'deki B bölgesi ortaya çıkarılmıştır.

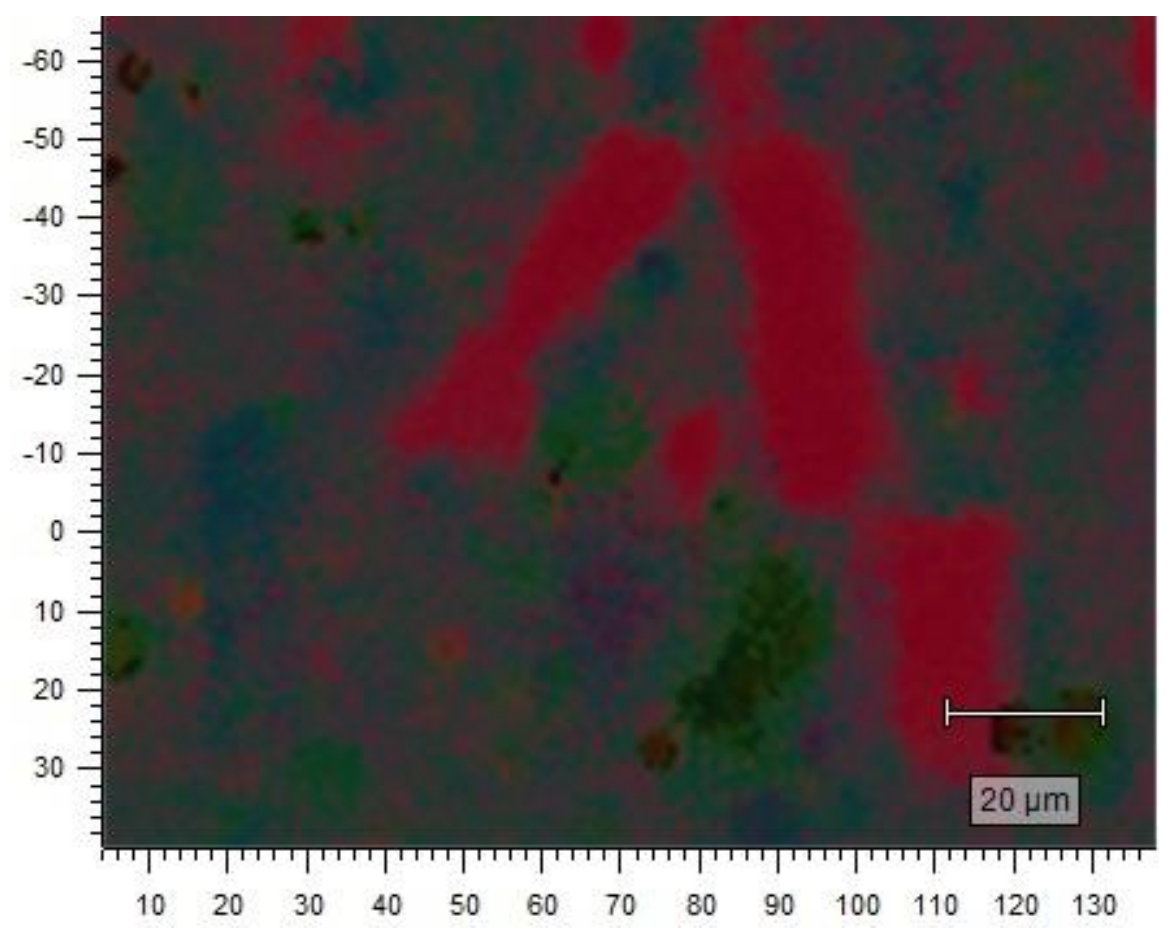

Şekil 4. Bilinmeyen kompozit malzeme içinde bulunan üç farklı yapının renkli spektral taramas1

Tüm bölgeler belirlendikten sonra aynı çekilen spektral veriler üst üste çakıştırıldığında Şekil 4'deki gibi bir yüzey elde edilmiştir. Bu yüzey üzerinden miktarsal oranın hesaplanabilmesi için kemometrik yöntem kullanılmıştır. Bu yöntemde, yazılıma kompozitin içinde bulunduğundan emin olunan, spektral veriler yüklenir. Program algoritması bu spektral verileri cihazın taradığı alandaki tüm spektrumlarla karşılaştırır ve malzemelerin yüzeyde bulunma oranlarını verir. Yapılan yüzeysel hesaplama hacimsel verilere dönüştürülerek kompozitteki malzemelerin hacimsel veya kütlesel karıştırma oranları yaklaşık olarak belirlenir. $\mathrm{Bu}$ işlem spektral 
verilerden elde edilen bilginin matematiksel bir algoritmaya aktarılmasına ve doğru değerlere yaklaşım yapmaya olanak sağlar. Yapısını belirlediğimiz kompozit de surası ile A'dan (iPP) hacimce \%60, B'den (KF) \%14 ve C'den (SiC) $\% 26$ olduğu hesaplanmıştır. Kompoziti oluşturan elemanların teorik yoğunluklarından yola çıkarak ağırlıkça karıştırma oranlarına geçilebilir.

\section{Sonuçlar}

Bilinmeyen kompozit malzemenin analiz sonucunda, polimer tabanlı bir kompozit olduğu ve bu polimerinden PP olduğu yapılan literatür taramas1 ve Raman spektral veri kütüphanesi eşleştirilmesi sonucunda görülmüştür. Malzeme içinde düzgün dağılmış ve ortalama parçacık boyutu 90 mikron olan seramik tabanl malzemenin, isıl iletkenlik arttırıcı olarak kullanılan $\mathrm{SiC}$ olduğu hem literatür araştırması hem de kütüphane taramasından net biçimde anlaşılmıştır. Geriye kalan üçüncü bileşenin uzunluğu ortalama $3 \mathrm{~mm}$ olan karbon fiber olduğu literatür taraması ile ortaya çıkarılmıştır. Kompoziti oluşturan malzemelerin miktarları kemometrik yöntemle hesaplanarak sırası ile \%60 iPP, \%26 SiC ve \%14 KF olarak bulunmuştur.

\section{Kaynaklar}

Ball, D. W. 2001. Theory of Raman spectroscopy. Spectroscopy, 16(11), 32-34.

Banwell, C.N. ve McCash, E. 1994. Fundamentals of Molecular-Spectroscopy. New York: McGrawHill.

Belu, A., Mahoney, C., Wormuth, K. 2008. Chemical imaging of drug eluting coatings: combining surface analysis and confocal Raman microscopy. Journal of Controlled Release, 126(2), 111-121.

Breitenbach, J., Schrof, W., Neumann, J. 1999. Confocal Raman-spectroscopy: analytical approach to solid dispersions and mapping of drugs. Pharmaceutical research, 16(7), 11091113.

Cai, W. B., Ren, B., Li, X. Q., She, C. X., Liu, F. M., Cai, X. W., Tian, Z.-Q. 1998. Investigation of surface-enhanced Raman scattering from platinum electrodes using a confocal Raman microscope: dependence of surface roughening pretreatment. Surface Science, 406(1-3), 9-22.

Caspers, P. J., Lucassen, G. W., Puppels, G. J. 2003. Combined in vivo confocal Raman spectroscopy and confocal microscopy of human skin. Biophysical journal, 85(1), 572-580.
Chance, K. V, Spurr, R. J. D. 1997. Ring effect studies: Rayleigh scattering, including molecular parameters for rotational Raman scattering, and the Fraunhofer spectrum. Applied optics, 36(21), 5224-5230.

Colthup, N. 2012. Introduction to infrared and Raman spectroscopy. Elsevier.

Dieing, T., Hollricher, O., Toporski, J. 2011. Confocal raman microscopy, (C. 158). Springer.

Gierlinger, N., Schwanninger, M. 2006. Chemical imaging of poplar wood cell walls by confocal Raman microscopy. Plant physiology, 140(4), 1246-1254.

Hartschuh, A., Sánchez, E. J., Xie, X. S., Novotny, L. 2003. High-resolution near-field Raman microscopy of single-walled carbon nanotubes. Physical Review Letters, 90(9), 95503.

Hollas, J. M. 1984. Fundamentals of molecular spectroscopy-banwell, CNT". Royal Soc. Chemistry Thomas Garham House, Science Park, Milton Road.

Keren, S., Zavaleta, C., Cheng, Z. dl, de La Zerda, A., Gheysens, O., Gambhir, S. S. 2008. Noninvasive molecular imaging of small living subjects using Raman spectroscopy. Proceedings of the National Academy of Sciences, 105(15), 5844-5849.

Keresztury, G. 2006. Raman Spectroscopy: Theory, Handbook of vibrational spectroscopy.

Klein, K., Gigler, A. M., Aschenbrenner, T., Monetti, R., Bunk, W., Jamitzky, F., ... Schlegel, J. 2012. Label-free live-cell imaging with confocal Raman microscopy. Biophysical journal, 102(2), 360-368.

Moerner, W. E., Fromm, D. P. 2003. Methods of single-molecule fluorescence spectroscopy and microscopy. Review of Scientific instruments, 74(8), 3597-3619.

Nielsen, A. S., Batchelder, D. N., Pyrz, R. 2002. Estimation of crystallinity of isotactic polypropylene using Raman spectroscopy. Polymer, 43(9), 2671-2676.

Okumura, H., Sakuma, E., Lee, J. H., Mukaida, H., Misawa, S., Endo, K., Yoshida, S. 1987. Raman scattering of $\mathrm{SiC}$ : application to the identification of heteroepitaxy of $\mathrm{SiC}$ polytypes. Journal of applied physics, 61(3), 1134-1136.

Qian, X., Wang, X., Zhong, J., Zhi, J., Heng, F., Zhang, Y., Song, S. 2019. Effect of fiber microstructure studied by Raman spectroscopy upon the mechanical properties of carbon fibers. Journal of Raman Spectroscopy. 
Raman, C. V., \& Krishnan, K. S. 1928. A new type of secondary radiation. Nature, 121(3048), 501.

Stuart, B. 2000. Infrared spectroscopy. Kirk Othmer Encyclopedia of Chemical Technology, 1-18.

Uzunbajakava, N., Lenferink, A., Kraan, Y., Volokhina, E., Vrensen, G., Greve, J., Otto, C.
2003. Nonresonant confocal Raman imaging of DNA and protein distribution in apoptotic cells. Biophysical journal, 84(6), 3968-3981.

Vardeny, Z., Ehrenfreund, E., Brafman, O., Horovitz, B. 1983. Resonant Raman scattering from amplitude modes in trans-(CH) $\mathrm{x}$ and-(CD) $\mathrm{x}$. Physical review letters, 51(25), 2326. 